\title{
One-Dimensional and Multi-Dimensional Studies of the Exocentric Distance Estimates in Frontoparallel Plane, Virtual Space, and Outdoor Open Field
}

\author{
J. Antonio Aznar-Casanova ${ }^{1}$, Elton H. Matsushima ${ }^{2}$, \\ Nilton P. Ribeiro-Filho ${ }^{3}$, and José A. Da Silva ${ }^{4}$ \\ ${ }^{1}$ Universidad de Barcelona, Spain \\ ${ }^{2}$ Universidade Federal Fluminense, Brazil \\ ${ }^{3}$ Universidade Federal do Rio de Janeiro, Brazil \\ ${ }^{4}$ Universidade de São Paulo, Brazil
}

The aim of this study is twofold: on the one hand, to determine how visual space, as assessed by exocentric distance estimates, is related to physical space. On the other hand, to determine the structure of visual space as assessed by exocentric distance estimates. Visual space was measured in three environments: (a) points located in a 2-D frontoparallel plane, covering a range of distances of $20 \mathrm{~cm}$; (b) stakes placed in a 3-D virtual space (range $\approx 330 \mathrm{~mm}$ ); and $(\mathrm{c})$ stakes in a 3-D outdoors open field (range $=45 \mathrm{~m}$ ). Observers made matching judgments of distances between all possible pairs of stimuli, obtained from 16 stimuli (in a regular squared $4 \times 4$ matrix). Two parameters from Stevens' power law informed us about the distortion of visual space: its exponent and its coefficient of determination (R2). The results showed a ranking of the magnitude of the distortions found in each experimental environment, and also provided information about the efficacy of available visual cues of spatial layout. Furthermore, our data are in agreement with previous findings showing systematic perceptual errors, such as the further the stimuli, the larger the distortion of the area subtended by perceived distances between stimuli. Additionally, we measured the magnitude of distortion of visual space relative to physical space by a parameter of multidimensional scaling analyses, the RMSE. From these results, the magnitude of such distortions can be ranked, and the utility or efficacy of the available visual cues informing about the space layout can also be inferred.

Keywords: visual space perception, depth perception, monocular and binocular vision, multidimensional scaling, stereopsis, visual psychophysics, exocentric space

En este estudio se pretendía cubrir un doble objetivo. Por un lado, determinar cómo el espacio visual, evaluado en términos de estimaciones de distancias exocéntricas, se corresponde con el espacio físico. Y, por otro lado, determinar la estructura del espacio visual a partir de las mismas estimaciones de distancias. Para ello, registramos la respuesta (métrica) de los observadores en tres entornos espaciales: (a) puntos localizados en un plano 2-D (frontoparalelo) en un rango de distancias de $20 \mathrm{~cm}$; (b) estacas vistas esteroscopicamente y situadas en un espacio virtual 3-D (rango de $33 \mathrm{~cm}$ ); y (c) estacas físicas dispuestas en un espacio abierto exterior (rango de $45 \mathrm{~m}$ ). Los observadores hicieron juicios de emparejamiento de distancias entre todos los posibles pares que se podían formar con 16 estacas (dispuestas en una matriz cuadrada regular de 4 filas $\times 4$ columnas). Utilizamos dos parámetros de la ley potencial de Stevens, que nos informaron de la distorsión percibida del espacio visual: el exponente y el coeficiente de determinación (R2). Los resultados permitieron ordenar la magnitud de la distorsión encontrada en cada entorno experimental, proporcionando información sobre la utilidad y eficacia de las claves de profundidad disponibles. Nuestros datos concuerdan con los obtenidos en estudios previos en mostrar una cierta anisotropía espacial que difiere en cada entorno. Adicionalmente, aplicamos el escalamiento multidimensional y medimos la distorsión a través del RECM, lo que también nos permitió ordenar la magnitud de las distorsiones en cada contexto, así como la eficacia de las claves visuales de distancia.

Palabras clave: percepción del espacio visual, percepción de la profundidad, visión monocular y binocular, escalamiento multidimensional, estereopsis, psicofísica visual, espacio exocéntrico

This research was supported by grants from the Spanish Ministerio de Ciencia y Tecnologia (Ref No. BSO2001-3639).

Correspondence concerning this article should be addressed to J. Antonio Aznar-Casanova, Department of Basic Psychology, Faculty of Psychology, University of Barcelona, Passeig Vall d'Hebron, 171, 08035-Barcelona (SPAIN). Tel: +34 933125145 . Fax: +34 93 40213 63. e-mail: jaznar2@ub.edu 
In the investigations about the accuracy of visual space under both full-cue and reduced-cue conditions, two frames of reference have usually been adopted. A well-known egocentric frame of reference (e.g., Foley, Ribeiro-Filho, \& Da Silva, 2004; He, Wu, Ooi, Yarbrough, \& Wu, 2004), in which people locate objects specifying a two-parameter vector (egocentric distance and direction) for a 2-D space or adding a slant parameter for a 3-D space; or an allocentric or exocentric frame of reference (e.g., Levin \& Haber, 1993; Kelly, Loomis, \& Beal, 2004; Matsushima, Oliveira, RibeiroFilho, \& Da Silva, 2005), specifying the relative distance between objects and their corresponding directions or orientations.

Research with distance estimates to assess the visual space has typically used the so-called direct scaling methods (Stevens, 1951, 1957), such as depth interval judgments (Gilinsky, 1951), also known as equal appearing intervals; ratio judgments, (e.g., bisection or general fractionation; Da Silva, 1983a); and magnitude estimates (Da Silva \& Dos Santos, 1982). However, more recently, research has been using perceptual measures based on visually directed actions (Loomis, Da Silva, Philbeck, \& Fukusima, 1996), such as visually directed walking, triangulation by pointing, and triangulation by walking. Nevertheless, results from these different research methodologies are not unequivocal, showing different structures of visual space: the former methods show large systematic errors and the latter show accuracy and smaller errors (Loomis, Da Silva, Fujita, \& Fukusima, 1992; Fukusima, Loomis, \& Da Silva, 1997; Philbeck, Loomis, \& Beall, 1997). One can conclude from these findings that the results of these investigations were task-dependent (e.g., Indow, 2004).

In contrast, from the psychophysical investigations, we also know that our space perception is not veridical (Sedgwick, 1986). The undershooting of distance estimates increases as viewing distance increases (Gogel, 1993; Loomis \& Philbeck, 1999). The most widely used mathematical model to provide an account of these data on visual space is Stevens' Power Law (Stevens, 1951, 1957), as stated for perceived distances:

$$
D^{\prime}=k \cdot D^{n}
$$

where $D^{\prime}$ is the perceived distance, $D$ the physical distance, and $k$ an arbitrary constant related to the scale or units used in the estimates.

The exponent $n$ in the power law represents the observer's sensitivity to perceive some property of a stimulus. Specifically, for the context of the metric of visual space, the slope $(\beta)$ of the rectified power law (linear regression fit) informs us about the ability to discriminate distances (accuracy of the mechanism). In short, the exponent of the power law reveals the relation between perceived distances and physical distances, and how changes in physical continuum impose changes on the perceived continuum (in fact, if the physical attribute changes by a constant ratio, the perceived magnitude will change by the same constant ratio). The coefficient of determination $\left(R^{2}\right)$ of linear regression informs us about the goodness-of-fit of data to the assumed relationship between perceived and physical distances in linear regression analysis. In other words, it is a measure of with how much certainty one can make predictions from a specific model (prediction power). In addition, the standard error informs us about the average error in the prediction of the model and it allows us to determine a confidence interval, which serves to infer whether two exponents are significantly different.

Traditionally, researchers have assumed that perceived distances are direct and linearly related to the physical distance, that is, they are related to physical distances as stated by a power function with exponents equal to 1 . Weist and Bell (1985), and Da Silva (1985) examined several studies using the power law to model data on visual space, and showed its importance and utility to determine the accuracy of perceived distances relative to the physical ones.

Another assumption about psychophysics of distance perception is to consider the exponents stable and reliable for all visual contexts and for different ranges of distances. Those assumptions are not fully supported by psychophysical findings, which presented influences of context and sensory modalities (Gescheider, 1997) and bias on reliability related to age and gender in a 2-D bisection task (Pierce, Jewell, \& Mennemeier, 2003), although this last piece of evidence was not unequivocal, since there are other studies in indoor and outdoor environments showing stability across time (Da Silva \& Fukusima, 1986).

Two studies accomplished by Teghtsoonian and Teghtsoonian $(1969 ; 1970)$ illustrate the importance of Stevens' law, by revealing that visual space is supported by an adaptive mechanism. In the first study, participants made verbal reports (magnitude estimates) of distances in natural indoor environments, either in a large classroom with a 1.5-2.4 m range of distances; or in a long corridor with a 1.5-13.5 m range). The power functions fitted to data showed the same mean slope in the two environments $(\beta=1.21)$. The second study was accomplished in an outdoor environment (range of distances $=1.5-14.4 \mathrm{~m}$ ) and reported a mean slope of power functions equal $.87(S D=.13)$. Comparing these findings, the exponents found for perceived distances in an indoor environment showed a positively accelerated relation to physical distances; conversely, outdoor environment exponents showed a negatively accelerated relation to physical distances.

Currently, studies have provided evidence (see Sedgwick, 1986) for a range of variations of exponents from .65 to 1.20 (Künnapas, 1960; Teghtsoonian \& Teghtsoonian, 1969; Da Silva, 1983b; Flückiger, 1991) for varying ranges of distances up to $300 \mathrm{~m}$. However, for targets further than 2 $\mathrm{km}$, exponents can drop to a lower value of .38 (Flückiger) when observers estimated the distances of boats on the Léman Lake (looking from Geneva toward Montreux), 
ranging from $.20 \mathrm{~km}$ to $2.25 \mathrm{~km}$. Relative size and angular declination of lake surface were the only depth cues available for observers in this environment.

In summary, the exponent value is greater than 1 ( $n>1$, overconstancy) in the observer's personal space; is nearly equal to 1 ( $n \approx 1$, constancy) when distances are located in action space; and is smaller than 1 ( $n<1$, underconstancy) as distances increase beyond action space. One can conclude that distance perception should be range, context, and taskdependent.

Most of the previous studies reported in space perception research used egocentric distance estimates. As there is evidence for range, context, and task-dependent influences on exponents, we investigated these three variables related to visual space, the slope $(\beta)$ of the rectified power law, the coefficient of determination $\left(R^{2}\right)$, and the standard error. In the following experiments, the observers' task was to match the distance between two previously seen stimuli, marking two other stimuli at the same location.

One of the aims of the present study was to determine the values of power law exponents of distance estimates in three different spatial contexts, namely a 2-D frontoparallel plane (Experiment 1), a 3-D virtual space (Experiment 2), and a real 3-D space (Experiment 3). Another aim was to examine the distortion or inaccuracy of visual space inherent to different environmental settings. Few investigations have explored the perceptual distortion of visual space (e.g., Loomis \& Philbeck, 1999; Koenderink, van Doorn, \& Lappin, 2000) and even fewer have explored visual psychophysics in large open-field environments (Da Silva, 1985). Distortion of visual space was measured in the same three different spatial contexts. In order to determine the accuracy in the encoding of spatial properties of physical space, we used the root mean squared error (RSME) parameter from multidimensional scaling (MDS) technique.

Experiment 1. Exocentric distance estimates in the frontoparallel plane (2-D space)

\section{Method}

\section{Observers}

Twelve volunteer students, 8 women and 4 men, mean age $22.6(S D=1.86)$ participated in this experiment, received course credit for their collaboration. All of them were naïve to the experimental objectives and their visual acuity was normal or corrected-to-normal. The stereoacuity was about $40 \mathrm{~s}$ arc as measured by Titmus and TNO stereoacuity tests.

\section{Stimuli and Apparatus}

Sixteen white dots $(6 \mathrm{~mm}$ diameter, luminance $=100$ $\mathrm{cd} / \mathrm{m}^{2}$ ) were regularly distributed (separated by $5 \mathrm{~cm}$ ) in a
$4 \times 4$ matrix shaped like a $15-\mathrm{cm}$ regular square, evenly distributed throughout the screen area, presented on a 22 " CRT monitor (Philips Brillance 202 P4) with $1024 \times 768$ pixels of resolution, on a black background (luminance $=$ $.008 \mathrm{~cd} / \mathrm{m}^{2}$ ). The stimuli were generated on a Pentium 4, $2.0 \mathrm{GHz}$, with responses made on a two-button mouse. A chinrest maintained an 80-cm observation distance. Each pair combined of the 16 dots (120 pairs) was randomly presented only once, for $3 \mathrm{~s}$.

\section{Procedure}

The participants' task was to match an exocentric distance between two dots by marking on the screen the remembered location of the previously presented dots. This task could be considered a direct method, specifically, magnitude production (Stevens, 1960). An experimental trial began with the presentation of a pair of dots for $3 \mathrm{~s}$, followed by a mask of colored circles $(2.5 \mathrm{~cm}$ diameter $)$ fulfilling the screen for another $3 \mathrm{~s}$. The mask prevented bias from possible after-effects of the vanishing stimuli on the response background. After the mask, the mouse was enabled, so participants could mark the locations of response dots, pressing the left button of the mouse. A sound (a beep about $500 \mathrm{~ms}$ ) announced the following trial.

\section{Results and Discussion}

Data and psychophysical function are summarized in Figure 1. Linear regression fit produced a very good fit $\left(R^{2}\right.$ $=.917$ ) and a slope (or exponent of Stevens' law) of 1.015, a value not different from constancy value, $n=1(t(10)=$ $.284, p>.05)$. This shows a tendency to constancy, indicating that changes in physical distance by a certain ratio will lead to changes by the same ratios. In other words, visual space is nearly veridical to physical space.

All participants (2-D Space)

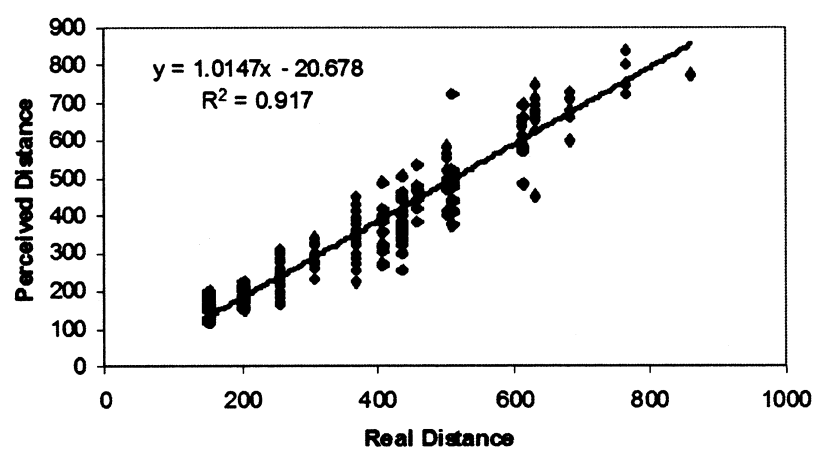

Figure 1. Perceived distances as a function of real distances, in centimeters. Linear regression fit is also presented, as well as its coefficient of determination $\left(R^{2}\right)$. 
Derived stimulus configuration (2-D Space) Euclidean Distance Model

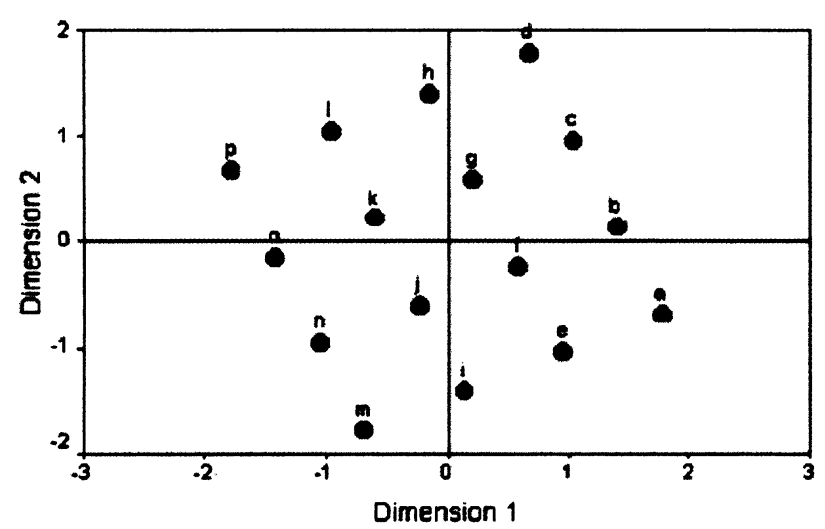

Derived stimulus configuration (2-D perceived space) Euclidean Distance Model

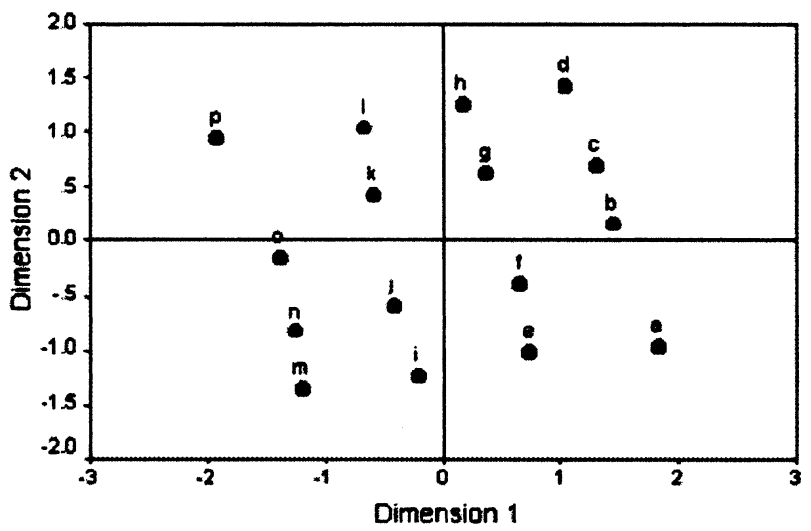

Figure 2. Left Panel: Derived stimuli configuration of physical space. Right Panel: Derived stimuli configuration of perceived space.

This result agrees with a previous one found with a different method, magnitude estimates, but in a similar 2D space with a small range of distances (Kerst, Howard, \& Gugerty, 1987). It also confirms the claims that distance perception is nearly veridical in the observer's immediate surroundings (Indow, 2004), that is, in his or her peripersonal space (Cutting \& Vishton, 1995).

Additionally, an MDS (Ascal procedure) was run on mean estimates of exocentric distances and are depicted in Figure 2. Parameters of goodness-of-fit, Kruskal's stress and coefficient of determination were produced for these twodimensional models (Figure 3). Stress determines how well a configuration fits the data. Lower values of stress, between 0 and .15, indicate good fit, with larger values associated with poor fit (Stalans, 1995). Coefficient of determination $\left(R^{2}\right)$ is also a measure of goodness-of-fit, derived from multiple $R$ correlation, and informs about the amount of variance in the dependent variable accounted for by the weighted combination of coordinates. $R^{2}$ ranges from 0 to 1 , with larger values indicating good fit (Stalans). The twodimensional model fits well to data, as indicated by stress $=.158$, indicating a good fit, and by coefficient of determination $\left(R^{2}=.895\right)$, equally showing a good fit.

Distortion of visual space relative to physical space was assessed by analyses of RMSE between perceived and physical locations in a 2-D representation of these spaces. The closer RMSE is to zero, the better the fit. In this case, lower values of RMSE are associated with accuracy of visual space. For 2-D frontoparallel plane, RSME from exocentric perceived distances reached .0063 , or translated into metric scale, an average of $6.6 \mathrm{~mm}$ of error in estimates. Comparing this error to the range of distances presented in the experiments $(50 \mathrm{~mm}-212.2 \mathrm{~mm})$, it is noted that observers were very accurate in peripersonal space in the frontoparallel plane, with a short range of distances. If one inspects Figure 4 , one can be sure that little or no distortion affects visual space relative to physical space.
Plot of linear fit (2D Perceived Space) Euclidean Distance Model

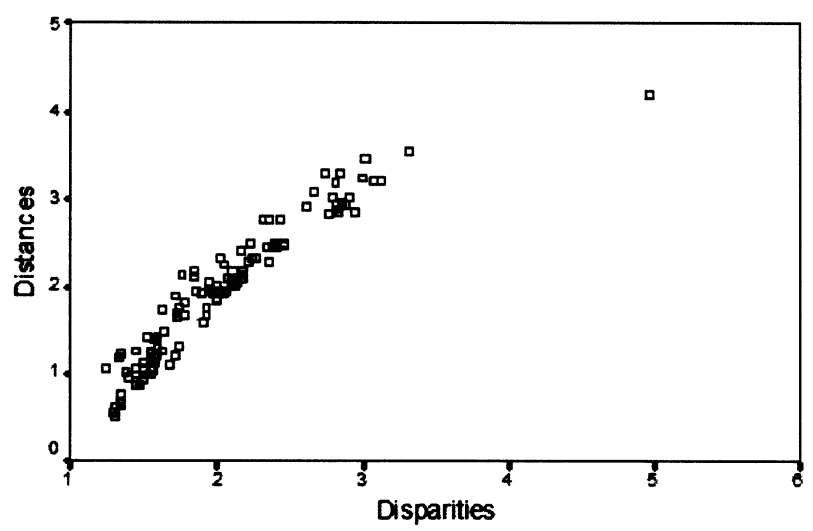

Figure 3. Linear fit of 2D perceived space (frontoparallel plane).

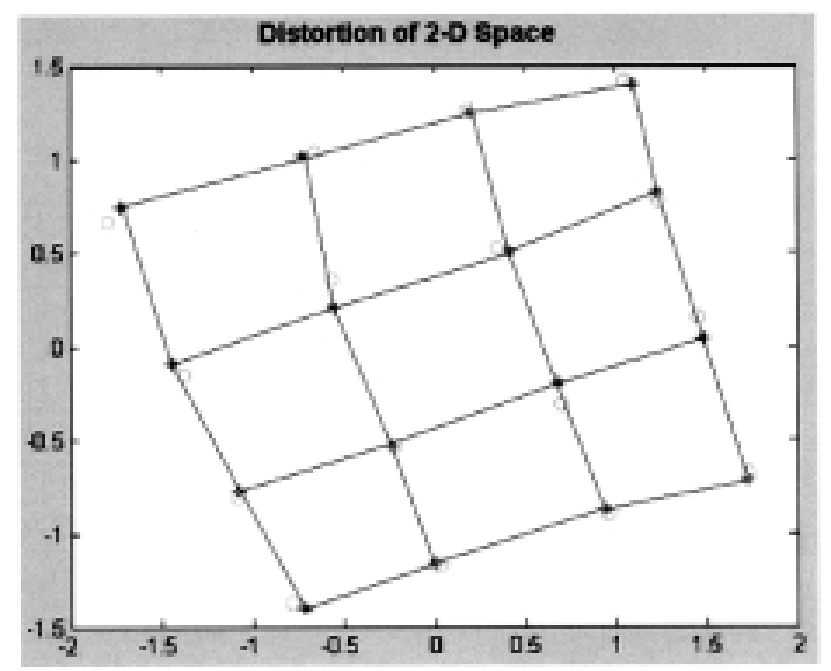

Figure 4. Comparison between structure of physical space and structure of visual space. Open circles represent physical locations of stimuli. Asterisks represent perceived locations. The grid formed by solid lines represents the structure of perceived space. 
Experiment 2. Exocentric distance estimates in the virtual 3-D space

\section{Method}

\section{Observers}

Ten volunteer students, 7 women and 3 men, mean age $21.3(S D=1.94)$ participated in this experiment, received course credit for their participation. All were naïve to the experimental objectives and had normal or corrected-tonormal visual acuity.

\section{Stimuli and Apparatus}

Stimuli were a pair from a set of 16 stakes (simulating $4.0 \mathrm{~mm}$ diameter $\times 80.0 \mathrm{~mm}$ high) organized in a regular $4 \times 4$ matrix, presented in a virtual environment. Each element of this configuration was placed 80 units $(78 \mathrm{~mm})$ from each other, thus the whole matrix side was 240 units $(234 \mathrm{~mm})$. These units correspond to the virtual space constructed by observers' visual system from binocular disparity information. OpenGL Library can work in millimeters considering the individual inter-pupillary distances. Therefore, the maximum distance simulated between a pair of stakes (main diagonals) was $330.94 \mathrm{~mm}$.

The stereoscopic system was generated by a Pentium 4, 2.0 GHz on a 19" monitor Philips Brillance 202 P4 through an accelerator graphic card (Wildcat VP880 Pro, by 3-D Labs Inc. Ltd.) to support OpenGL graphics, programmed in C++ by using the GLUT (Graphic Library Utility), which stands for OpenGL Utility Toolkit. This system configuration was also used to present the scenes on the virtual 3-D space to observers wearing LCD shutter goggles synchronized to the system. A chinrest maingained a $100-\mathrm{cm}$ constant observation distance. Each pair combined from the 16 stakes (120 pairs) was randomly presented only once for $3 \mathrm{~s}$.

\section{Procedure}

The participants' task was the same as Experiment 1, to match an exocentric distance between two stimuli by marking on the screen the remembered locations of the previously presented stimuli. An experimental trial began with a sound (500-ms beep) and the presentation of a pair of stakes for $3 \mathrm{~s}$, followed by a mask of colored circles $(2.5$ $\mathrm{cm}$ diameter) fulfilling the screen for another $3 \mathrm{~s}$. After the mask, mouse was enabled, so participants could mark the locations of response dots, pressing the left mouse button. Another beep (500 ms) announced the following trial.

\section{Results and Discussion}

Data and psychophysical function are summarized in Figure 5. Linear regression fit produced a poor fit $\left(R^{2}=\right.$
.696) and a slope of .633, very far from the constancy exponent, $t(7)=2.967, p=.021$. This exponent indicates perceptual underconstancy, which means that changes in physical distance by a certain ratio will lead to changes by increasingly smaller ratios.

One possible explanation for this underconstancy is the common finding of many space perception investigations conducted in virtual environments. There is evidence that the use of a head-mounted display leads to deficits of binocular function after only $10 \mathrm{~min}$ of immersion (Mon-Williams, Wann, \& Rushton, 1993). This is probably caused by the shift in heterophoria, so the visual system becomes unable to compensate for the heterophoria. Another possibility is the conflict of visual cues such as accommodation and fusional vergence, in fact, it is a variable conflict (rather than a stable conflict) of accommodation and fusional vergence that is problematic for the perception of egocentric distances in virtual 3-D scenes (Wann, Rushton, \& Mon-Williams, 1995). Fields of view severely limited in their dimensions, problems in the accuracy of stereographic systems, even limitations of the quality of scenes simulated (non-photorealistic) have all been considered as explanations to the underconstancy of egocentric distance in virtual environments (Rolland, Gibson, \& Arierly, 1995; Ellis \& Menges, 1997; Witmer \& Sadowski, 1998; Loomis \& Knapp, 2003). Recent research provides some answers to these issues. The restriction of field of view can be ruled out as a cause of underconstancy (Creem-Regehr, Willemsen, Gooch, \& Thompson, 2005) as well as the quality of scenes simulated (Thompson et al., 2004). Besides these recent findings, the issue remains to be answered.

The only foreseeable technical solution would be a system that monitors the eye movements and adjusts the image plane depth by some kind of servo-lens system. Unfortunately, no current eye-monitoring system seems to meet the requirements of resolution, stability, and real-time transmission to allow this usage in virtual reality systems.

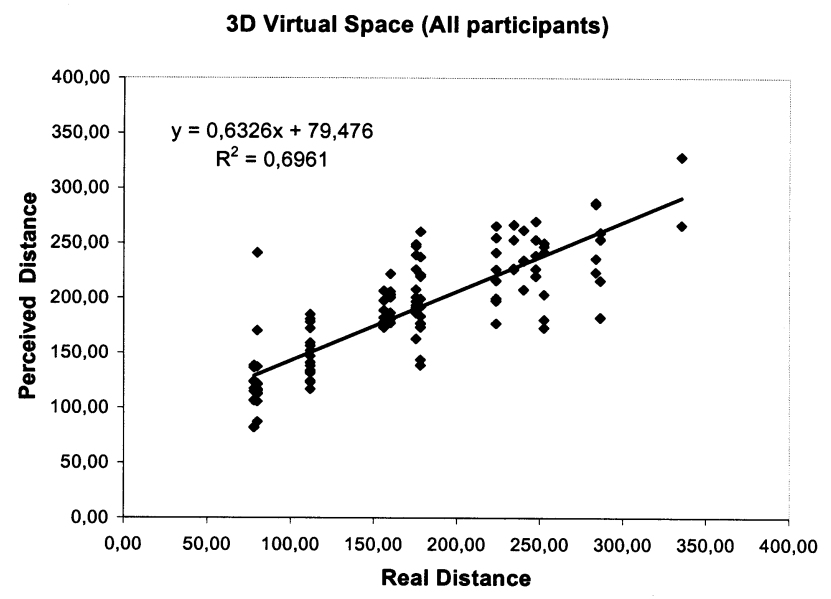

Figure 5. Perceived distances as a function of real distances, in millimeters. Linear regression fit is also presented, as well as its coefficient of determination $\left(R^{2}\right)$. 

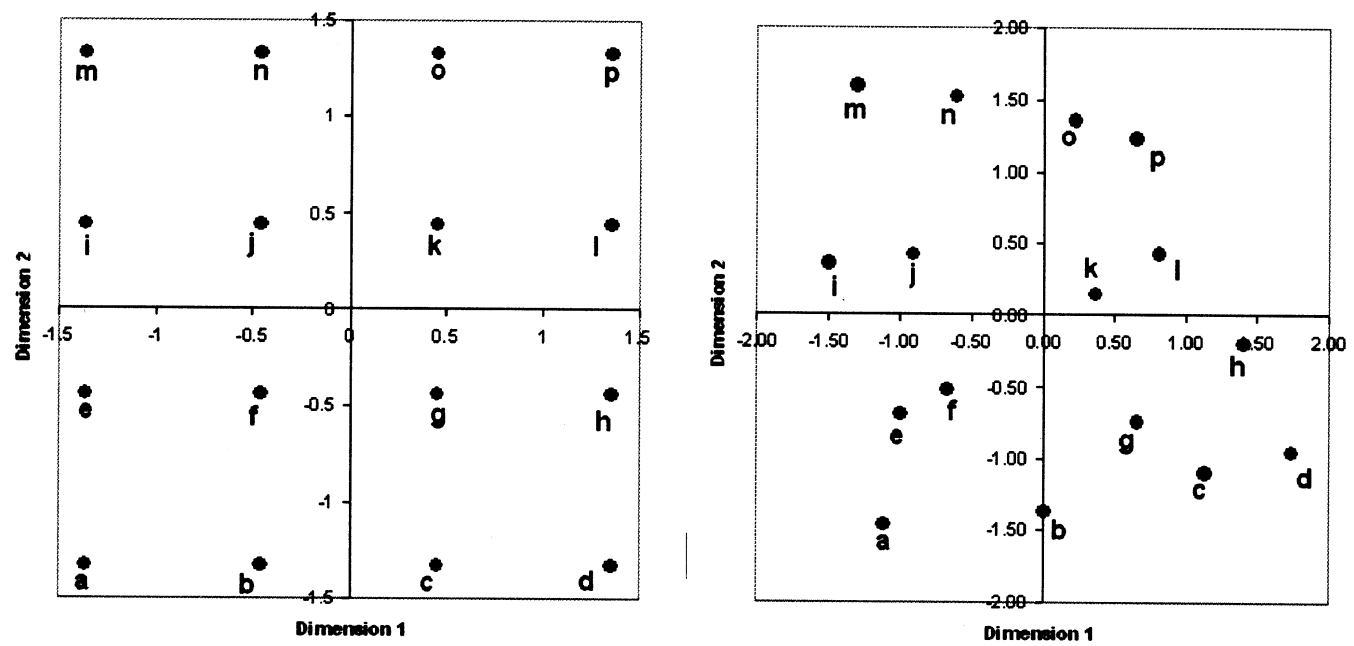

Figure 6. Left Panel: Derived stimuli configuration of physical space. Right Panel: Derived stimuli configuration of perceived space.

Complementarily, a similar MDS data analyses (Experiment 1) was run on these data. The original as well as the derived layouts from the observers' estimates of the stimuli configuration can be seen in Figure 6. Stress (.151) and $R^{2}(.849)$ both indicate good fit of the two-dimensional model of visual space, as can be seen in Figure 7. Thus, the following analyses could be claimed to be reliable.

Figure 8 depicts the structure of visual space as assessed by a 3-D virtual space. Large distortion relative to physical space can be seen in this figure. RSME (.026, in linear values, $2.6 \mathrm{~cm}$ ) confirms this interpretation of 2-D plots. Comparing these errors with the range used in Experiment 3, which was $7.8 \mathrm{~cm}-33.1 \mathrm{~cm}$, we found a distortion of visual space that reaches almost $33 \%$ of a physical distance in this space.

This confirms a common finding of experimental research on the psychophysics of virtual reality spaces, a large underconstancy of distances simulated in virtual environments (Loomis \& Knapp, 2003). This underconstancy is robust and is found for a variety of environmental conditions (Thompson et al., 2004; Creem-Regehr et al., 2005). A possible explanation yet to be determined is the variable conflict between accommodation and fusional vergence in virtual 3-D scenes (Wann et al., 1995).

Experiment 3. Exocentric distance estimates in a real outdoors space (3-D): monocular and binocular viewing

\section{Method}

\section{Observers}

Three volunteer students, 1 man and 2 women, mean age 23.6 years $(S D=2.34)$ participated in this experiment, for course credit. All were naïve to the experimental
Pld of linear fit (perceived distances) Euclidean Distance Moded (3-D Virtual Space)

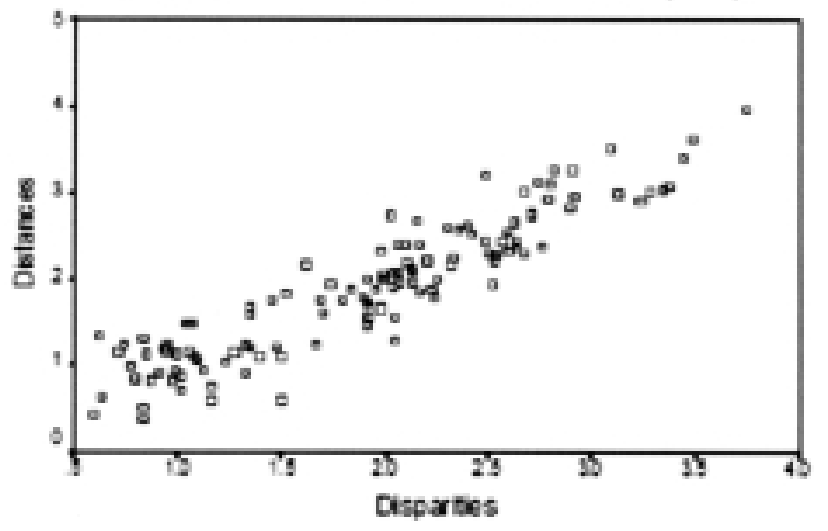

Figure 7. Linear fit of perceived space.

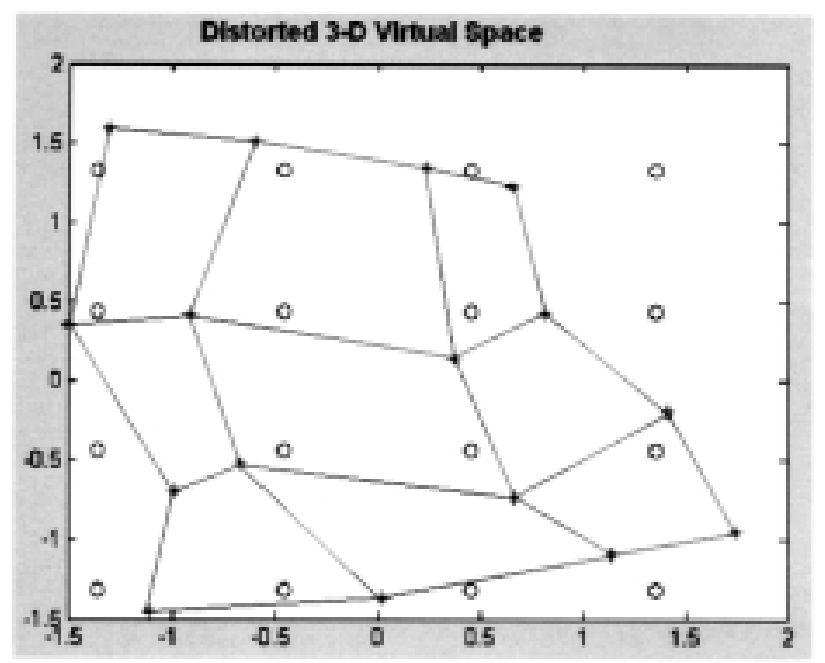

Figure 8. Comparison between structure of physical space and structure of visual space. Open circles represent physical locations of stimuli. Asterisks represent perceived locations. The grid formed by solid lines represents the structure of perceived space. 
objectives and had normal or corrected-to-normal visual acuity. The stereoacuity was about $40 \mathrm{~s}$ arc as measured by Titmus and TNO stereoacuity tests.

\section{Stimuli and Apparatus}

The regular squared $4 \times 4$ matrix $(45 \mathrm{~m} \times 45 \mathrm{~m})$ of 16 stimuli locations were built in a natural outdoors open field (a football stadium, $90 \mathrm{~m}$ depth $\times 47 \mathrm{~m}$ width). Each stimulus was distant from its adjacent by $15 \mathrm{~m}$. Four traffic cones $(60 \mathrm{~cm}$ high $\times 50 \mathrm{~cm}$ diameter), two of them were the stimuli subtending the exocentric distances and two others were the response stimuli. Vantage point was approximately $2.12 \mathrm{~m}$ from a corner of the matrix. Monocular masks were used to induce monocular viewing conditions.

\section{Procedure}

After visual acuity and eye dominance tests, observers received instructions to adjust the positions of traffic cones to match the distance of two other previously seen traffic cones. Observers only viewed pairs of stimuli from the vantage point. Participants could see the scenes either monocularly (with their dominant eye) or binocularly. The task followed a simple rule that considered an exocentric frame of reference. If the previous exocentric distance was horizontal (relative to the main axis of layout), the observer must match a saggital distance, and when the distance was saggital, the observer must match a horizontal one. If previous distance was not orthogonal, the observers should

\section{MONOCULAR OPEN FIELD (3-D) EXPLORATION}

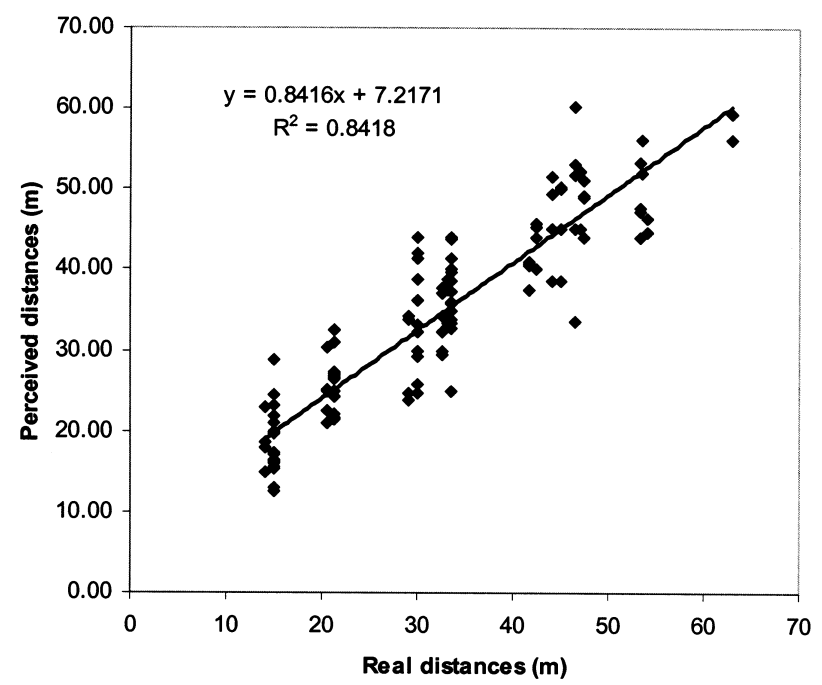

Figure 9. Perceived distance as a function of real distance, in meters, of monocular viewing condition groups. Linear regression fit is also presented, as well as its coefficient of determination $\left(R^{2}\right)$. match a horizontal distance to every previous distance presented under the diagonal of layout containing the vantage point, and a saggital distance to every distance above the diagonal. The matching was made by adjusting the position of a second traffic cone relative to a fixed one in front of the vantage point.

\section{Results and Discussion}

Data and psychophysical functions are summarized in Figures 9 and 10. The linear functions presented an acceptable adjustment to data under monocular and binocular viewing conditions, $R^{2}=.841$ and $R^{2}=.867$, respectively. Slopes for monocular and binocular viewing conditions, $\beta$ $=.842$ and $\beta=.915$, respectively, were also not different from the constancy value, $t(2)=2.632, \mathrm{p}>.05$; and $t(2)=$ $1.589, \mathrm{p}>.05$, respectively.

These parameters agree with part of those previously reported in other studies, also accomplished in outdoor environments (Teghtsoonian \& Teghtsoonian, 1970; Da Silva, 1983b; Da Silva \& Fukusima, 1986). Comparing the magnitude production (matching procedures) of the present investigation to magnitude estimates (Teghtsoonian \& Teghtsoonian; Da Silva \& Fukusima), one finds similar exponents $(n=.846$ and $n=.915$-ours; $n=.87-$ Teghtsoonians'; $n=.91, n=.90$, and $n=.85-$ Da Silva \& Fukusima's), although ours are not different from the constancy value. When comparing magnitude production to ratio estimates (Da Silva), we again found similar exponents ( $n=.846$ and $n=.915$-ours; $n=1.05$ and $n=.90$-theirs), although 32-m range of distances were different from

\section{BINOCULAR OPEN FIELD (3-D) EXPLORATION}

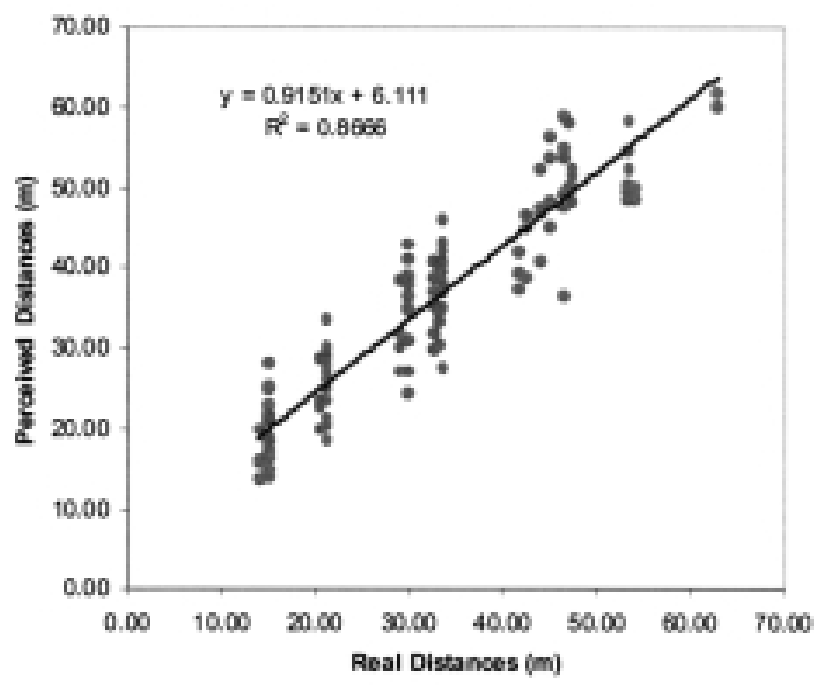

Figure 10. Perceived distance as a function of real distance, in meters, of binocular viewing condition groups. Linear regression fit is also presented, as well as its coefficient of determination $\left(R^{2}\right)$. 
constancy value in Da Silva's investigation, while our $\approx 49$ $\mathrm{m}$ range produced perceptual constancy in all-cue conditions. Taken together, these comparisons may indicate that the variability of power law exponents is more task-dependent than range-dependent.

Subsequent data analyses were the same as in Experiments 1 and 2. The original as well as the derived layout from the observers' estimates of the stimuli configuration can be seen in Figure 11. For monocular viewing, stress was .125 and $R^{2}=.890$, both indicating a good fit of the 2-D model of visual space as can be seen in left panel of Figure 12. For binocular viewing, the fit of 2$\mathrm{D}$ model was also good, as confirmed by stress $=.116$ and $R^{2}=.905$. Thus, one can reliably describe visual space with the proposed 2-D model.
Comparing the structure of visual space to that of physical space (see Figure 13), we found that monocular visual space was more distorted than the binocular one (linear $\mathrm{RSME}=1.86 \mathrm{~m}$, and linear $\mathrm{RSME}=.87 \mathrm{~m}$, respectively). Moreover, distortion was relatively small when compared to the range of distances presented to observers, $1.5 \mathrm{~m}$ up to $46.5 \mathrm{~m}$, reaching a maximum of $\approx 4.13 \%$ under monocular viewing and $\approx 1.93 \%$ under binocular viewing.

Our analyses of the structure of visual space presented a common finding of research on space perception: Accuracy is directly proportional to the availability of visual cues (Künnapas, 1968; Cutting \& Vishton, 1995; Cutting, 2002). Excluding binocular information by means of imposing a monocular viewing condition, thus preventing the effectiveness of binocular disparity and fusional vergence
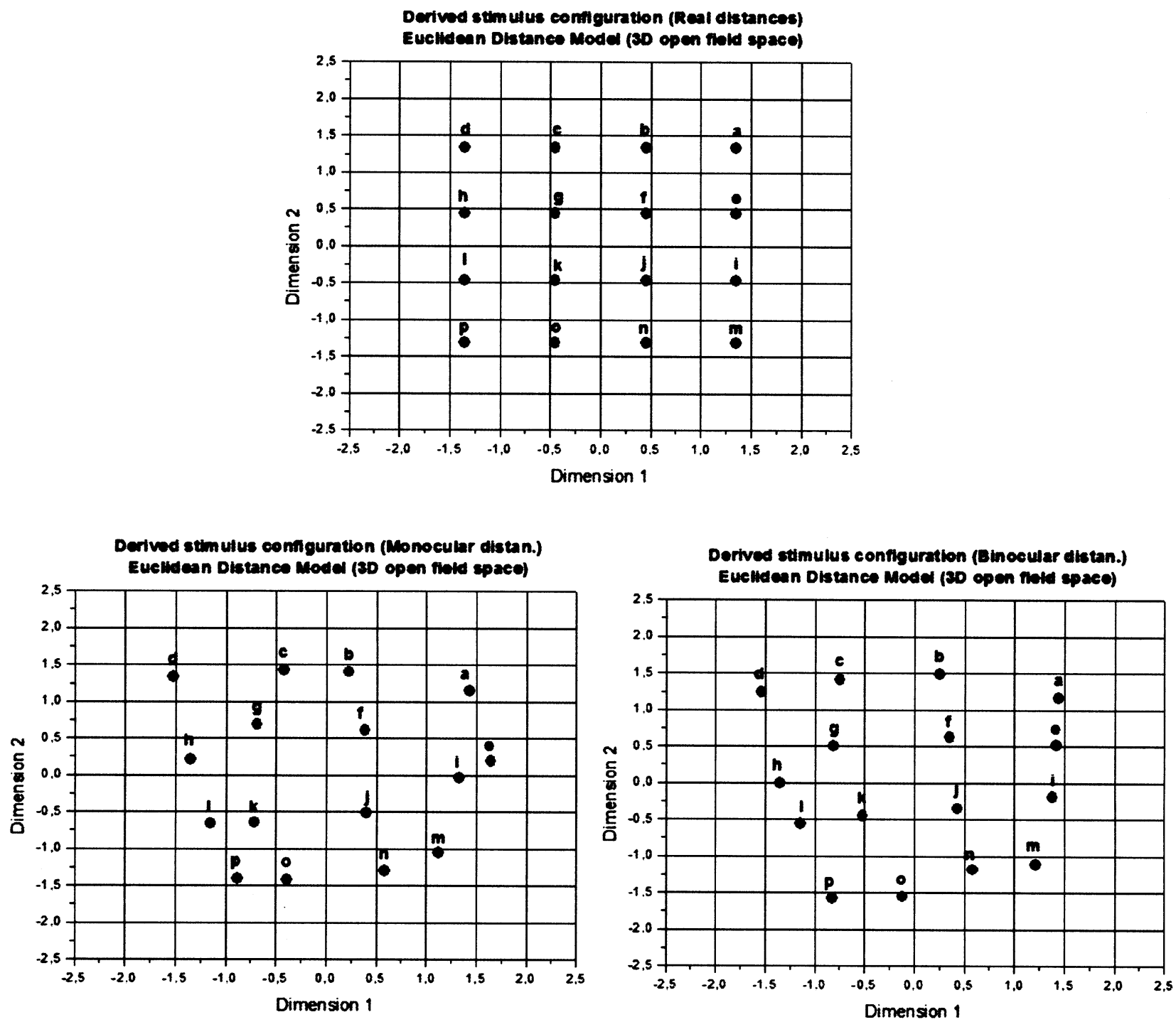

Figure 11. Upper Panel: Derived stimuli configuration of physical space. Lower Left Panel: Derived stimuli configuration of perceived space under monocular viewing. Lower Right Panel: Derived stimuli configuration of perceived space under binocular viewing. 
Plot of linear fit (Monocular distan.) Euclidean Distance Model (30 open field Space)

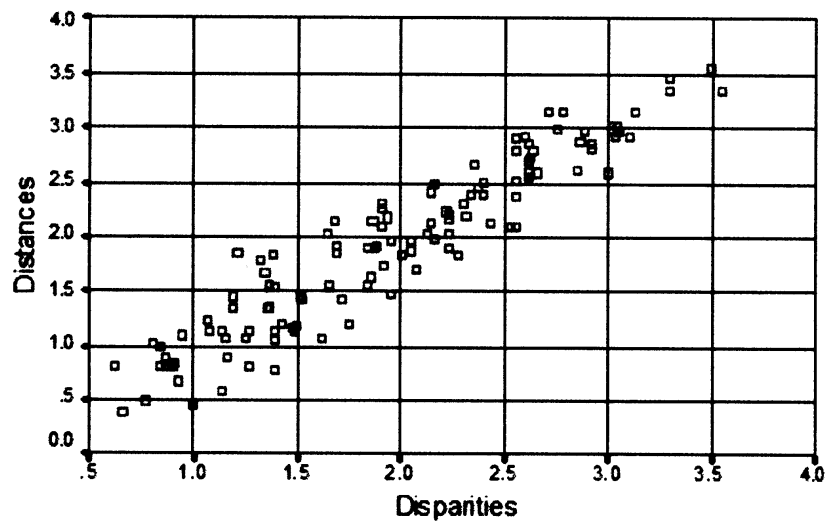

Plot of linear fit (Binocular distan.) Euclidean Distance Model (3D open field Space)

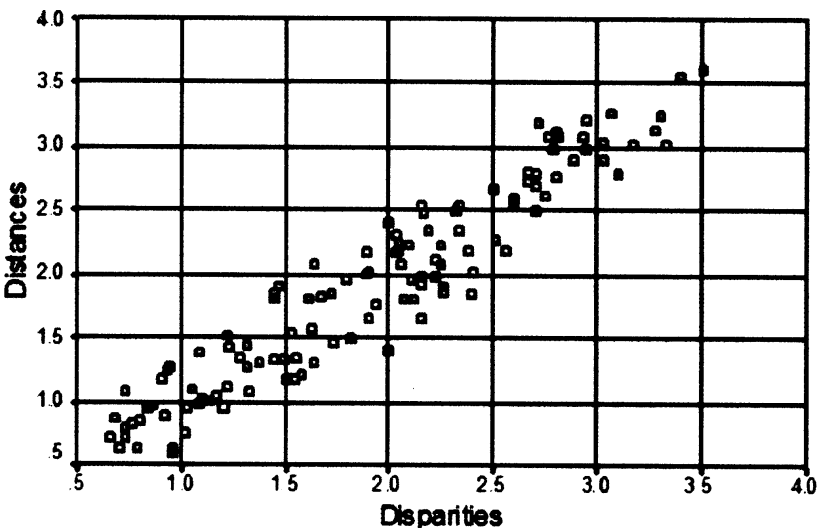

Figure 12. Left Panel: Linear fit of perceived space under monocular viewing. Right Panel: Linear fit of perceived space under binocular viewing.
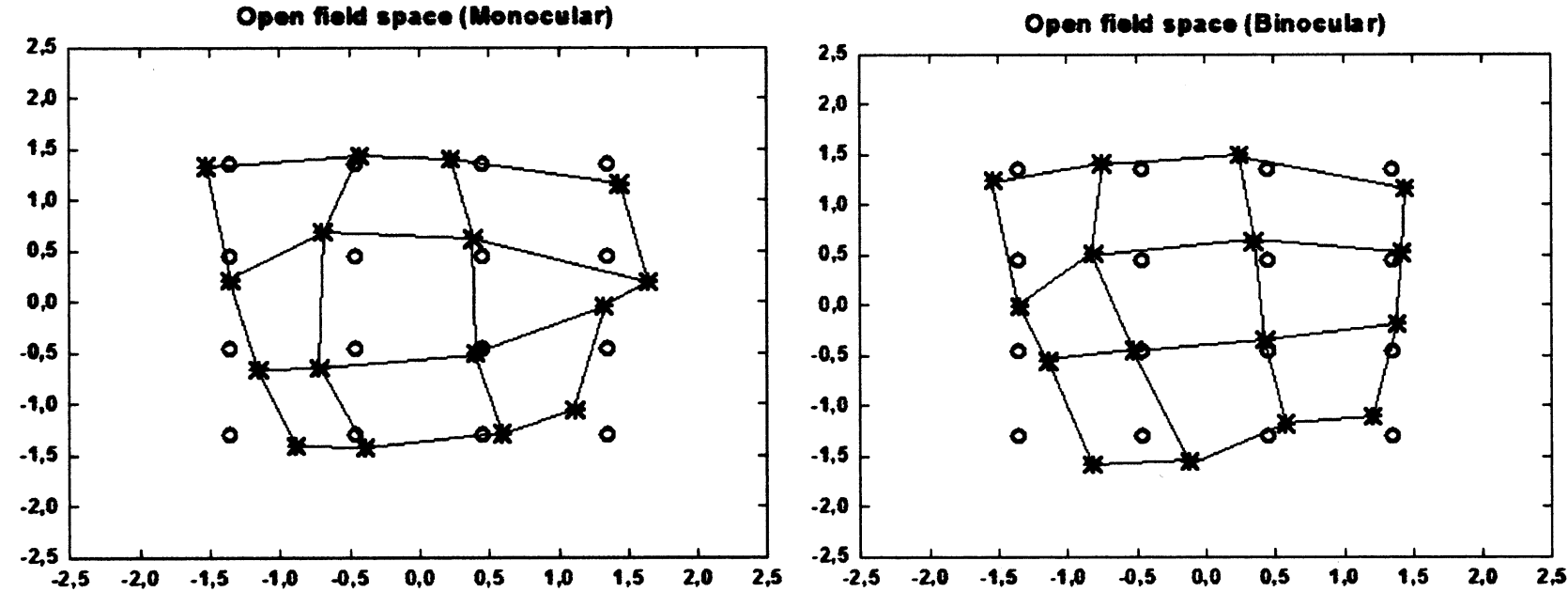

Figure 13. Comparison between structure of physical space and structure of visual space. Upper Panel summarizes the structure of visual space under monocular viewing; Lower Panel summarizes the structure of visual space under binocular viewing. Open circles represent physical locations of stimuli. Asterisks represent perceived locations. The grid formed by solid lines represents the structure of perceived space.

information, increased the RSME intrinsic to visual space. When binocular information was again allowed, errors decreased as a consequence. Visual space in the range used in this experiment $(1.5 \mathrm{~m}-46.5 \mathrm{~m})$ should be much more compressed relative to physical space, however, a full-cue condition produced a quasi-veridical visual space in both viewing conditions.

\section{Comparing Exponents and General Discussion}

Comparing the four exponents produced in Experiments 1,2 , and 3 to perceptual constancy value $(n=1)$, one could determine the perceptual pattern associated with each spatial environment imposed (Figure 14). A one-way ANOVA, 5 conditions (2-D frontoparallel plane, 3-D virtual space, 3D monocular real space, 3-D binocular real space, and perceptual constancy), on individual exponents indicates that there are significant deviations from perceptual constancy in those spaces, $F(4,25)=11.551, p=.000 . T$ test post hoc analyses indicated that only $3-\mathrm{D}$ virtual space is different from the constancy value, $n=1(p=.001)$, whereas all the other environmental conditions did not differ from constancy $(p>.05)$.

Exponents from frontoparallel plane in 2-D space and from full-cue 3-D real-world space showed constancy, and in 3-D virtual space, a large underconstancy (although there was a poor fit of power law function). 2-D visual space is more accurate due to the small range of distances imposed on this investigation. In 3-D visual spaces, natural conditions 


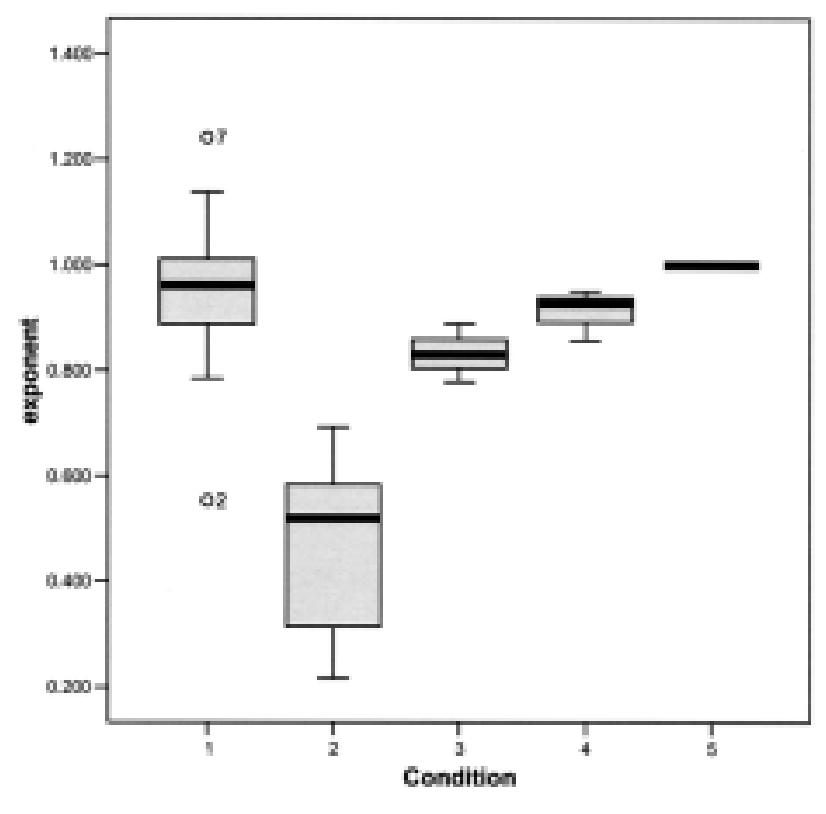

Figure 14. Exponents and confidence intervals for 2-D frontoparallel space (Condition 1), 3-D virtual space (2), 3-D real monocular space (3), and 3-D real binocular space. Constancy reference value $(n=1)$ is also presented as Condition 5 .

improve accuracy, as it seems that virtual space resents the lack of some visual information that exists in real-world spaces, which is yet to be determined. Furthermore, adding visual cues, such as binocular information, improved sensitivity of visual space, providing evidence for many previous findings in visual research (Cutting, 2002; Cutting \& Vishton, 1995; Künnapas, 1968).

This pattern of sensitivities of visual space to the physical properties of scenes could be a hint for the structure and the organization of the phenomenal geometry of visual space. Probably, visual space architecture must be composed by two or three "spaces" and their different geometries. Peripersonal space must be a nearly Euclidean geometry to provide the proper sensitivity found in perceptual responses. As the range of distances involved increases, the geometry of visual space becomes negatively accelerated compared to physical space. More investigations on virtual visual space are needed to understand its deficits and how they prevent perceptual constancy in this experimental condition.

The mapping between visual and physical space is fundamental for an understanding of perceptual processing and perceptual experience. Providing an account of visual space geometry must be one the most important objectives for any research on visual space perception. Our results provide accounts of visual space geometry in three different environments or spatial conditions. In a 2-D frontoparallel space, results indicated high levels of accuracy in visual space relative to physical space. Considering the findings of visual research, our results add another piece of evidence for perceptual accuracy in a rarely used task (magnitude production by a matching task).

In a 3-D virtual environment, our results were in agreement with several other findings that also suffered from the intrinsic properties of visual perception in immersive virtual environments: severe compression and distortion of visual space. There is no consensus about the relevant properties of virtual stimuli that are responsible for this outcome. Cue conflict and accommodation disorders could be alternative explanations, which remains to be tested.

In 3-D real environment, another common finding from visual perception research was replicated, the relation between cue availability and accuracy in judgments. The more cues available, the higher the accuracy in the matching task. The distortion found in these results is very small compared to the distance range used in the experiments. One may claim that a natural outdoor environment must provide all the sources of visual information needed for accurate responses. Others may claim that the procedure used in the matching task lacks control over some intervening variables, such as the familiar size of the assistant moving the cones to adjust their position. The assistant's height must serve as a hint to determine egocentric distances. However, we claim the validity of these data, as our task was to match an exocentric distance, and research evidence indicates that there is a dissociation between visual perception for ego- and exocentric distances (Kudoh, 2005; Loomis et al., 1992), and also there was independence between distance and size perception (Haber \& Levin, 2001).

Considering our results, it can be stated that 2-D spaces, when in a peripersonal range of distances, must be accurate and veridical. 3-D real spaces, in outdoor environments, are also accurate and near veridical when under full-cue conditions. 3-D virtual spaces are an issue that remains to be fully explored. There are many features of virtual stimuli that demand more investigation in order to establish which information is responsible for the outcome of virtual reality research.

\section{References}

Creem-Regehr, S.H., Willemsen, P., Gooch, A.A., \& Thompson, W.B. (2005). The influence of restricted viewing conditions on egocentric distance perception: Implications for real and virtual indoor environments. Perception, 34, 191-204.

Cutting, J.E. (2002). Reconceiving perceptual space. In H. Hecht, M. Atherton, \& R. Schwartz (Eds.), Perceiving pictures: An interdisciplinary approach to pictorial space. Cambridge: MIT Press.

Cutting, J.E., \& Vishton, P.M. (1995). Perceiving layout and knowing distances: The integration, relative potency, and contextual use of different information about depth. In W. Epstein \& S.J. Rogers (Eds.), Perception of space and motion (pp. 69-117). San Diego, CA: Academic Press. 
Da Silva, J.A. (1983a). Ratio estimation of distance in a large open field. Scandinavian Journal of Psychology, 24, 343-345.

Da Silva, J.A. (1983b). Scales for measuring subjective distance in children and adults in a large open field. The Journal of Psychology, 113, 221-230.

Da Silva, J.A. (1985). Scales for perceived egocentric distance in a large open field: Comparison of three psychophysical methods. The American Journal of Psychology, 98, 119-144.

Da Silva, J.A., \& Dos Santos, R.A. (1982). Scaling apparent distance in a large open field: Presence of a standard does increase the exponent of the power function. Perceptual and Motor Skills, 55, 267-274.

Da Silva, J.A., \& Fukusima, S.S. (1986). Stability of individual psychophysical functions for perceived distance in natural indoor and outdoor settings. Perceptual and Motor Skills, 63, 891-902.

Ellis, S.R., \& Menges, B.M. (1997). Judgments of the distance to nearby virtual objects: Interaction of viewing conditions and accommodative demand. Presence: Teleoperators and Virtual Environments, 6, 452.

Flückiger, M. (1991). La perception d'objects lointains. In M. Flückiger \& K. Klaue (Eds.), La perception de l'environnement (pp. 221-238). Lausanne: Delachaux et Niestlè.

Foley, J.M., Ribeiro-Filho, N.P., \& Da Silva, J.A. (2004). Visual perception of extent and the geometry of visual space. Vision Research, 44, 147-156.

Fukusima, S.S., Loomis, J.M., \& Da Silva, J.A. (1997). Visual perception of egocentric distance as assessed by triangulation. Journal of Experimental Psychology: Human Perception and performance, 23, 86-100.

Gescheider, G.A. (1997). Psychophysics: The fundamentals $\left(3^{\text {rd }}\right.$ ed.). Mahwah: NJ: Erlbaum.

Gilinsky, A.S. (1951). Perceived size and distance in visual space. Psychological Review, 58, 460-482.

Gogel, W.C. (1993). The analysis of perceived space. In S.C. Masin (Ed.), Foundations of perceptual theory (pp. 113-182). Amsterdam: Elsevier.

Haber, R.N., \& Levin, C.A. (2001). The independence of size and distance perception. Perception \& Psychophysics, 63, 1140-1152

He, Z.J., Wu, B., Ooi, T.L., Yarbrough, G., \& Wu, J. (2004). Judging egocentric distance on the ground: Occlusion and surface integration. Perception, 33, 789-806.

Indow, T. (2004). Global structure of visual space. London: World Scientific.

Kelly, J.W., Loomis, J.M., \& Beal, A.C. (2004). Judgments of exocentric direction in large-scale space. Perception, 33, 443-454.

Kerst, S.M., Howard, Jr., J.H., \& Gugerty, L.J. (1987). Judgment accuracy in pair-distance estimation and map sketching. Bulletin of the Psychonomic Society, 25, 185-188.

Koenderink, J.J., van Doorn, A.J., \& Lappin, J.S. (2000). Direct measurement of curvature of visual space. Perception, 29, 6979.

Kudoh, N. (2005). Dissociation between visual perception of allocentric distance and visually directed walking of its extent. Perception, 34, 1399-1416.
Künnapas, T.M. (1960). Scales for subjective distance. Scandinavian Journal of Psychology, 1, 187-192.

Künnapas, T. (1968). Distance perception as a function of available visual cues. Journal of Experimental Psychology, 77, 523-529.

Levin, C.A., \& Haber, R.N. (1993). Visual angle as a determinant of perceived interobject distance. Perception \& Psychophysics, 54, 250-259.

Loomis, J.M., Da Silva, J.A., Fujita, N., \& Fukusima, S.S. (1992). Visual space perception and visually directed action. Journal of Experimental Psychology: Human Perception and Performance, 18, 906-921.

Loomis, J.M., Da Silva, J.A., Philbeck, J.W., \& Fukusima, S.S. (1996). Visual perception of location and distance. Current Directions in Psychological Science, 5, 72-77.

Loomis, J.M., \& Knapp, J.M. (2003). Visual perception egocentric distance in real and virtual environments. In L.J. Hettinger \& M.W. Haas (Eds.), Virtual adaptive environments (pp. 21-46). Mahwah, NJ: Erlbaum.

Loomis, J.M., \& Philbeck, J.W. (1999). Is the anisotropy of perceived 3-D shape invariant across scale? Perception \& Psychophysics, 61, 397-402.

Matsushima, E.H., Oliveira, A.P., Ribeiro-Filho, N.P., \& Da Silva, J.A. (2005). Visual angle as determinant factor for relative distance perception. Psicológica, 26, 97-104.

Mon-Williams, M., Wann, J.P., \& Rushton, S. (1993). Binocular vision in a virtual world: Visual deficits following the wearing of a head-mounted display. Ophthalmic and Physiological Optics, 13, 387-391.

Philbeck, J.W., Loomis, J.M., \& Beall, A.C. (1997). Visually perceived location is an invariant in the control of action. Perception \& Psychophysics, 59, 601-612.

Pierce, C.A., Jewell, G., \& Mennemeier, M. (2003). Are psychophysical functions derived from line bisection reliable? Journal of the International Neuropsychological Society, 9, 7278.

Rolland, J.P., Gibson, W., \& Arierly, D. (1995). Towards quantifying depth and size perception as a function of viewing distance. Presence: Teleoperators and Virtual Environments, 4, 24-49.

Sedgwick, H.A. (1986). Space perception. In K.R. Boff, L. Kaufman, \& J.P. Thomas (Eds.), Handbook of human perception and performance (pp. 21.1-21.57). New York: Wiley.

Sedgwick, H.A. (2001). Visual space perception. In E.B. Goldstein (Ed.), Handbook of perception (pp. 129-167). Oxford: Blackwell.

Stalans, L.J. (1995). Multidimensional scaling. In L.G. Grimm \& P.R. Yarnold (Eds.), Reading and understanding multivariate statistics (pp.137-168). Washington, DC: American Psychological Association.

Stevens, S.S. (1951). Mathematics, measurement, and psychophysics. In S.S. Stevens (Ed.), Handbook of experimental psychology. New York: Wiley.

Stevens, S.S. (1957). On the psychophysical law. Psychological Review, 64, 153-181. 
Stevens, S.S. (1960). The psychophysical sensory function. American Scientist, 48, 226-254.

Teghtsoonian, M., \& Teghtsoonian, R. (1969). Scaling apparent distance in natural indoor settings. Psychonomic Science, 16, 281-283.

Teghtsoonian, R., \& Teghtsoonian, M. (1970). Scaling apparent distance in a natural outdoor setting. Psychonomic Science, 21, 215-216.

Thompson, W.B., Willemsen, P., Gooch, A.A., Creem-Regehr, S.H., Loomis, J.M., \& Beall, A.C. (2004). Does the quality of the computer graphics matter when judging distance in visually immersive environments? Presence: Teleoperators and Virtual Environments, 13, 560-571.
Wann, J.P., Rushton, S., \& Mon-Williams, M. (1995). Natural problems for stereoscopic depth perception in virtual environments. Vision Research, 35, 2731-2736.

Weist, W.M., \& Bell, B. (1985). Stevens' exponent for psychophysical scaling of perceived, remembered, and inferred distance. Psychological Bulletin, 98, 457-470.

Witmer, B., \& Sadowski, Jr., W. (1998). Nonvisually guided locomotion to a previously viewed target in real and virtual environments. Human Factors 40, 478-488.

Received December 15, 2005 Review received February 10, 2006 Accepted April 27, 2006 